DRAFT

\title{
Tracking Giving Across Generations
}

\author{
Richard Steinberg and Mark Wilhelm* \\ Department of Economics, IUPUI and \\ the Center on Philanthropy at Indiana University
}

November 2003

Prepared for New Directions for Philanthropic Fundraising.

* Mailing address: Department of Economics, IUPUI, 425 University Boulevard, Indianapolis, Indiana 46202. E-mail addresses:

rsteinbediupui.edu (Richard Steinberg) and mowilheldiupui.edu (Mark Wilhelm). The authors are grateful to Ted Flack for suggesting some ways practitioners might use this data. Richard steinberg thanks the Centre for Nonprofit and Philanthropic Studies at Queensland Institute of Technology for their hospitality during the writing of this section. Gratitude is also expressed to The Atlantic Philanthropies for providing the financial support necessary to launch the Center on Philanthropy Panel study (COPPS). COPPS results from a partnership between the Center on Philanthropy at Indiana University and the Survey Research Center at the University of Michigan. 
The Center on Philanthropy Panel study reports on the giving and volunteering of more than 7400 households in 2001 and 2003 and the household's composition, income, and wealth over the previous 30 years. This data will help researchers and fundraisers understand many new aspects of philanthropy.

\title{
Tracking Giving Across Generations
}

\author{
Richard Steinberg and Mark Wilhelm
}

What effect does parental role-modeling have on the philanthropic behaviors of their adult children? When adult children inherit their parents' wealth, are they as generous with this money as they are with their own earnings? These are two of the questions we are trying to answer using a wonderful new data source, the center on Philanthropy Panel study (COPPS). In this paper, we describe this data and the many questions it can help to answer. We focus on two types of questions -- those relating to giving across generations, and those relating to improving fundraising practice.

\section{The Center on Philanthropy Panel Study}

In contrast to an annual series of cross-sectional surveys in which a different random sample of respondents is selected for each year's survey, a panel study selects a random sample in the first year and then reinterviews those same respondents year after year. COPPS is part of a larger data collection project -- the Panel study of Income Dynamics (PSID), conducted by the Survey Research Center at the 
University of Michigan.

Since its initial interview year in 1968, the PSID has become the nation's longest running, nationally-representative, social science panel survey. Although the major focus of data collection is economic and demographic, health, social, and psychological indicators are also included. The PSID has been used in more than 2,000 scientific studies and is the only social science project to make the National Science Foundation's "nifty fifty" list of the fifty projects that have had important effects on everyday life.

In 2001 COPPS added a series of questions on giving and volunteering to the PSID's rich database. The questions ask about amounts given for several charitable purposes (religious, combined funds, basic needs (poverty relief), health, education, youth and family services, the arts, neighborhoods, the environment, international aid). There are also questions about volunteering. Both series have been expanded for the 2003 wave, and we hope to continue these series indefinitely in future waves of the PSID.

While there are other notable datasets on giving and volunteering, none combine the advantages of COPPS as a panel survey linked to a broader and longer-term panel. First, panel data has become the gold standard across social science disciplines for detecting cause and effect relationships. Suppose that, say, higher levels of income are associated with higher levels of giving. This hints that one causes the other, but certainly does not prove the point. With panel data, the analyst will see whether respondents who personally enjoyed an increase in income gave more following that 
increase, and this is far more persuasive evidence of cause and effect.

Second, COPPS lets one study giving and volunteering over the life course. Panel data follow the same households over time, tracing out their entire life histories. Third, COPPS permits intergenerational analysis of giving and volunteering. This is because the PSID employs "genealogical sampling," continuing to interview adult children after they leave their households of origin. Fourth, COPPS supplements data on giving and volunteering with a broad range of high-quality contextual data, including income, wealth, work hours, wages, health, family structure and demographic data. Such data are typically unavailable in other surveys of giving and volunteering; in the PSID they stretch back 33 years. Finally, with a sample of 7,406 households, COPPS is more than twice the size of the next largest survey of giving and volunteering in the United States. Thus, the size of any effects on giving can be more precisely and reliably measured.

One of us compared the quality of data from the first wave of COPPS with that in five other studies of giving in the U.S. (Wilhelm, 2003). He finds that COPPS provides the highest quality data since the National Study of Philanthropy (NSP) in 1974. The NSP, fielded as part of the Filer Commission report, oversampled high-income households, and so is generally thought to have the most accurate survey estimates of giving at the high end. COPPS data was closer than that provided by the other four surveys to NSP giving by the most generous $10 \%$ of respondents. The same was true in comparing 
COPPS with income tax data, which also accurately tracks high-end giving. In addition, COPPS excelled in two other dimensions -- a high survey response rate, and a dramatically lower occurrence of item nonresponse to the questions about amounts given.

\title{
Giving Across Generations
}

Table 1 provides an illustration of the type of question that can be answered using COPPS data. Here, we report differences in giving across three generations: prewar (born 1945 or earlier), baby boom (born 1946-1964), and generation X (born 1965 and after). The respective age categories in 2001 are 56 and older, 37-55, and 36 and younger. We report overall differences, and differences in giving to religious organizations for religious purposes and to "secular" organizations (which include religiously-affiliated hospitals, schools, and social service agencies as well as gifts to all organizations that are not affiliated with a religion).

\section{TABLE 1 GOES ABOUT HERE}

\author{
Giving levels vary across generations for many reasons. For \\ example, the average prewar respondent is wealthier than the average \\ respondent from generation $x$, so it is not surprising that the former \\ give more. However, in table 1, we have tried to statistically \\ adjust the survey results to remove the impact of wealth and many \\ other differences to get at a pure generation effect. Table 1
}


reports predicted levels of giving per person if everyone in the sample were a member of the indicated generation but otherwise retained their other characteristics (family income, wealth, sex of the family head, marital status, number of children, age of youngest child, employment status, health, race, ethnicity, region, city size, education, and religious affiliation). Thus, if everyone in the sample were members of the prewar generation, gifts per person would be about $\$ 1764$; if all were baby boomers, $\$ 1254$; and if all were generation $\mathrm{x}, \quad \$ 1100$.

The difference between the prewar and later generations is strikingly large, suggesting that later generations are about 1/3 less generous. This difference is both numerically large and statistically significant (which means we would very rarely see such large differences in other samples unless average generosity really did differ across generations). Baby boomers seem a bit more generous than generation x'ers, but this difference is small and not statistically significant.

In rows 2 and 3 of Table 1 , we see how the generations differ in giving to religious vs. nonreligious organizations. The striking result is that almost all the drop-off in giving by the later generations is due to a decline in religious giving. Giving to other causes differs little across the generations, and the small differences reported in row 3 are not statistically significant. To interpret these results, we should be clear on the precise definitions of both categories. Respondents were asked 'Did you make any donations specifically for religious purposes or spiritual 
development, for example to a church, synagogue, mosque, TV or radio ministry? Please do not include donations to schools, hospitals, and other charities run by religious organizations. I will be asking you about those donations next.' (PSID, 2001 question T2). This was recorded as a religious gift. Nonreligious giving is everything else: donations to combined funds (e.g., United Way, Catholic Charities, United Jewish Appeal, etc.), to help people with basic needs, for health care purposes, for educational purposes, to youth and family services, for improving neighborhoods, to the arts, for the environment, for international aid, and open-ended purposes the respondent could mention. These were reported separately, but are combined in the present paper. Although these latter purposes are 'nonreligious' in the sense that their primary purpose is not worship or spiritual development, donors may consider religious affiliation in deciding whether to support them.

Table 2 reports on giving by generation in much more detail. The first row shows the share of respondents who made a gift. Thus, 80\% of respondents from the prewar generation made gifts totaling at least $\$ 25$ (those making smaller gifts were not queried further). Baby boomers were similar, with 75\% making a gift, and only 53\% of gen x'ers giving. This means that it makes a great difference whether we report the average gift by someone who is a donor (row 3) or by all respondents (row 2), as the latter category includes many zero values in the average. We can now split the generational differences into two parts -- that due to reduced likelihood of making a gift, and that due to reduces size of gifts by donors. We 
see that boomers who give give almost the same amount as prewar donors (\$2222 vs. \$2269), so the difference in average giving between these generations is mostly due to the lower proportion of givers in the former (75\% vs. 80\%). In contrast, gen-x'ers are both less likely to give and less generous when giving.

\section{TABLE 2 GOES ABOUT HERE}

A few donors make enormous gifts, and these gifts have great impact on the reported average. Thus, we also report the median gift for all respondents (row 4) and for donors (row 5). The median gift is the gift reported by the middle guy, in that half the sample gave a larger amount and half a smaller amount. Because there is no ceiling on the largest gift that can be made, but there is a floor (even the stingiest cannot give less than nothing), the median gift is much lower than the average. To capture high-end giving, we also report giving by donors in the 95th percentile (row 6). Only 5 percent of the respondents made larger gifts than the values reported in this row.

\section{How Does One Generation Affect Giving by the Next?}

At gatherings of philanthropic practitioners the question "How can parents most effectively encourage the development of their children's philanthropic values?" is a sure-fire discussion starter. Most practitioners have formed opinions about this based on their 
family's experience, the experiences of friends, and, perhaps, their professional experience providing advice to philanthropists who want to pass their values onto their children. Advice is also available from the many books on children and money (e.g., Gallo and Gallo 2002). During the December holidays, the New York Times runs features in which families describe how they are passing on philanthropic traditions to their children.

Social scientists also are interested in how helping behavior develops in children and, in particular, the role parents play in that development. Much of what is known about the development of children's helping behavior comes from the developmental psychology literature. However, this literature concerns short-term behavior in laboratory settings, and one wonders whether results carry over into adult behaviors resulting from real-world experiences.

Philanthropic practitioners are, of course, ultimately interested in donations made during adulthood. However, much less is known about how parents affect the adulthood giving of their children because the data necessary to conduct nationally-representative studies are extremely expensive to collect. There are two reasons for this: (1) data have to be collected from both parents and their adult children, and (2) a wide range of information must be collected. COPPS provides a wealth of information, enabling researchers to make some progress here.

We are currently involved in two research projects that explore parental influences on the giving of their adult children. Neither study is complete at this time, and so we do not report results here. 
In the first (Wilhelm et al., 2003) we estimate the strength of the relationship between the current giving of parents and their adult children. Half the group of adult children in COPPS whose parents are still alive and participating in the survey are baby boomers and half are generation $\mathrm{X}$. In the second (Steinberg et al., 2003) we examine how adult children spend their inheritances. Specifically, we estimate the parents' propensity to make annual gifts out of their own wealth and compare this with the adult childs' propensity to give out of their inherited wealth. This will let us see whether the coming large wealth transfer (Havens and Schervish, 1999) is likely to increase or decrease annual giving.

\section{Using COPPS to Advance the Practice of Fundraising}

Obviously, there is much more to learn from copPS about patterns of giving. In the remainder of this paper we speculate on how the results from future studies could be used to improve the practice of fundraising. We suggest that there are potential uses in targeting solicitation efforts, predicting the effect of changes in the economy or public policy on giving, benchmarking the success of campaigns, and persuading donors that their gifts will not endanger their financial health over the life cycle. Unlike internal studies using proprietary data about the success of individual campaigns, these studies will produce evidence derived from the experience of multiple campaigns that can be shared with the fundraising community. 


\section{Targeting}

Campaign efforts are expensive. Donor markets are often segmented, and every effort should be made to direct efforts toward those segments of the market most likely to respond positively. Existing studies tell us a lot about patterns of giving across donors at a point in time. We know that on average, those with higher income, wealth, level of education, and age give more than others. However, for example, we do not know whether this generosity is due to higher levels of income, or due to some hidden trait that makes the donor both earn more and give more. Thus, we do not know to what extent someone whose own income goes up will give more. Consequently, we do not know for sure that those whose income suddenly increases are good prospects for new solicitation efforts. Studies using COPPS will allow us to follow individual donors as these factors change while their hidden traits remain constant, and so learn the real indicators of generosity.

In addition, COPPS will reveal the characteristics of donors who give regularly, year after year. This understanding can be used to direct prospecting efforts toward those who will respond not just once, but many times in the future. Further, copps can be used to figure out the lifetime value of gifts made by donors having different characteristics.

COPPS will also allow us to study the history of giving to each of the surveyed causes and learn more about the likely success of mailing lists derived from giving to other causes. For instance, suppose we found that those who give to the arts for the first time 
are more likely to give toward educational purposes two years later, but no more likely to give toward religious purposes two years later. Then, mailing lists of new donors to the arts would be a good purchase for those prospecting for new education donors and a poor purchase for those prospecting for new donors toward religious purposes.

Finally, copps allows us to study the effect of many factors not included in other available surveys. For example, there is extensive detail on the history of the various components of wealth and income. There are measures of expenditures on housing, automobiles, and other components of household consumption. Therefore, copPs can be used to ask whether these components are correlated with charitable giving. Moreover, data allow us to learn whether those who take higher financial risks are more or less likely to donate, and whether those recovering from bankruptcy are good prospects. Beyond expenditure data, there are data on the make and model of the family's cars and whether these cars were purchased new or used. If these factors are correlated with any aspect of giving, the application to targeting is immediate.

\section{Predicting}

How does a local disaster affect local giving to various causes? How do changes in state laws regarding the regulation, accountability, and taxation of organizations affect giving in that state?

Currently, the only way to learn the answer is to live through such a change. However, the COPPS sample is large enough that we can 
obtain reliable information at the state level for many states. To the extent this information is transferable, we can improve our ability to predict giving outcomes. For example, from learning how donors to each cause and in each income class react to, say, an earthquake in California or a scandal involving nonprofit hospitals in New York, we can predict how donors in other states will react to similar changes, and to do so at the time the change first occurs.

\section{Benchmarking}

How do your donors compare with donors to other charities serving related purposes? Is the difference due to differences in the income, wealth, and other characteristics of your donor pool or to problems or successes in your campaign? COPPS data provide generalizable information on average giving for donor pools with the characteristics of your campaign and those of comparison campaigns. From the history of giving, you can benchmark whether your donors are upgrading their annual gifts at rates comparable to other campaigns, after adjusting for differences in donor pools.

\section{Persuasion}

Rosenberg (1994) points out that the chief barrier to increased giving by the wealthy is unwarranted fear of financial misfortune. Donors are afraid that too much giving will deplete their wealth. He also argues that this fear is excessive, and that most donors could give far more without endangering their ability to enjoy retirement and pass on wealth to their heirs. COPPS can be used to generate 
more evidence to persuade donors that their fear is excessive because it can illustrate how the wealth of real donors changed over the lifetime following major gifts. The data are not ideal for this purpose, as COPPS has a representative sample including only a few wealthy donors, but this may suffice to assuage donor anxiety.

\section{References}

Gallo, E. and Gallo, J. Silver Spoon Kids: How Successful Parents Raise Responsible Children. Chicago: Contemporary Books, 2002.

Havens, J. and Schervish, P. "Millionaires and the Millennium: New Estimates of the Forthcoming Wealth Transfer and Prospects for a Golden Age of Philanthropy." Social Welfare Research Institute Working Paper. Chestnut Hill, MA: Boston College, 1999.

Panel Study of Income Dynamics. Available online at http://psidonline.isr.umich.edu/.

Rosenberg, C. N. Wealthy and Wise: How You and America Can Get the Most Out of Your Giving. Boston: Little, Brown, 1994.

Steinberg, R. and Wilhelm, M. "Patterns of Giving and Volunteering in COPPS 2001." Working Paper. Indianapolis: IUPUI Department of Economics, 2003 . 
Steinberg, R., Wilhelm, M., Brown, E. and Rooney, P. "Inheritance and Charitable Donations." Working Paper. Indianapolis: IUPUI Department of Economics, 2003.

Wilhelm, M. 2003. "The Distribution of Giving in Six Surveys." Working Paper. Indianapolis: IUPUI Department of Economics, 2003.

Wilhelm, M., Brown, E., Rooney, P. and Steinberg, R. 2003. "The Intergenerational Transmission of Generosity." Working Paper. Indianapolis: IUPUI Department of Economics, 2003.

RICHARD STEINBERG is Professor of EConomics, Philanthropic Studies, and Public Affairs and Associate Director of the Center on Philanthropy Panel Study (COPPS) at Indiana University Purdue University Indianapolis (IUPUI) .

MARK WILHELM is Associate Professor of Economics and Philanthropic Studies and Director of COPPS at IUPUI.

\section{Table 1: Giving Across Generations}

\begin{tabular}{||c|c|c|c||}
\hline & Pre-War & Baby Boom & Generation X \\
\hline Any Gift & $\$ 1,764.00^{\mathrm{xxx}, \mathrm{bbb}}$ & $\$ 1,254.00^{\mathrm{ppp}}$ & $\$ 1,100.00^{\mathrm{ppp}}$ \\
\hline Religion & $\$ 1,169.00^{\mathrm{xxx}, \mathrm{bbb}}$ & $\$ 752.00^{\mathrm{ppp}}$ & $\$ 660.00^{\mathrm{ppp}}$ \\
\hline
\end{tabular}

$-14-$ 


\begin{tabular}{||c|c|c|c|}
\hline & Pre-War & Baby Boom & Generation X \\
\hline Other than Religion & $\$ 595.00$ & $\$ 501.00$ & $\$ 440.00$ \\
\hline \hline
\end{tabular}

Notes:

1) In this table, we report the average level of predicted giving if everyone in the sample became a member of the indicated generation but otherwise retained their other characteristics (family income, wealth, sex of the family head, marital status, number of children, age of youngest child, employment status, health, race, ethnicity, region, city size, education, and religious affiliation). Details of this calculation are reported in Steinberg and Wilhelm (2003). 2) Statistical significance levels are reported as superscripts. The superscript ' $x$ ' indicates the value for this generation is significantly different from the value for generation $x$. The superscript ' $\mathrm{p}$ ' indicates a difference from the prewar generation, and 'b' indicates a difference from baby boomers. A single-letter superscript indicates a difference at the .10 level of significance. Double-letter superscripts indicate a difference at the .01 level, and triple-letter superscripts indicate a difference at the .001 level.

Source: Steinberg and Wilhelm, 2003 


\section{Table 2: Giving Across Generations: Details}

\section{Any Gift}

\begin{tabular}{||c|c|c|c|c|}
\hline & Everyone & Prewar & Baby Boom & Generation \\
\hline $\begin{array}{c}\text { Percent who Give } \\
\text { Sample Average Gift }\end{array}$ & $\$ 1,328.00$ & $\$ 1,788.00$ & $\$ 1,662.00$ & $\$ 532.00$ \\
\hline $\begin{array}{c}\text { (includes non-givers) } \\
\text { Sample Average Gift }\end{array}$ & $\$ 1,942.00$ & $\$ 2,269.00$ & $\$ 2,222.00$ & $\$ 1,025.00$ \\
\hline $\begin{array}{c}\text { (excludes non-givers) } \\
\text { Sample Median Gift }\end{array}$ & $\$ 303.00$ & $\$ 620.00$ & $\$ 500.00$ & $\$ 40.00$ \\
\hline $\begin{array}{c}\text { (includes non-givers) } \\
\text { Sample Median Gift }\end{array}$ & $\$ 775.00$ & $\$ 1,080.00$ & $\$ 928.00$ & $\$ 400.00$ \\
\hline $\begin{array}{c}\text { (excludes non-givers) } \\
\text { Sample 95th Percentile }\end{array}$ & $\$ 5,600.00$ & $\$ 6,386.00$ & $\$ 6,700.00$ & $\$ 3,000.00$ \\
\hline $\begin{array}{c}\text { (includes non-givers) } \\
\text { Number in Sample }\end{array}$ & 4616 & 1117 & & \\
\hline $\begin{array}{c}\text { Predicted Average Gift } \\
\text { (includes non-givers) }\end{array}$ & $\$ 1,328.00$ & $\$ 1,764.00$ & $\$ 1,254.00$ & $\$ 1,100.00$ \\
\hline \hline
\end{tabular}




\section{Giving Across Generations: Details (continued)}

\section{Religious Gift}

\begin{tabular}{|c|c|c|c|c|}
\hline & Everyone & Prewar & Baby Boom & $\begin{array}{c}\text { Generation } \\
\text { X }\end{array}$ \\
\hline Percent who Give & $47.00 \%$ & $62.00 \%$ & $51.00 \%$ & $31.00 \%$ \\
\hline $\begin{array}{l}\text { Sample Average Gift } \\
\text { (includes non-givers) }\end{array}$ & $\$ 823.00$ & $\$ 1,168.00$ & $\$ 991.00$ & $\$ 339.00$ \\
\hline $\begin{array}{l}\text { Sample Average Gift } \\
\text { (excludes non-givers) }\end{array}$ & $\$ 1,744.00$ & $\$ 1,888.00$ & $\$ 1,936.00$ & $\$ 1,099.00$ \\
\hline $\begin{array}{l}\text { Sample Median Gift } \\
\text { (includes non-givers) }\end{array}$ & $\$ 0.00$ & $\$ 300.00$ & $\$ 50.00$ & $\$ 0.00$ \\
\hline $\begin{array}{l}\text { Sample Median Gift } \\
\text { (excludes non-givers) }\end{array}$ & $\$ 700.00$ & $\$ 1,000.00$ & $\$ 960.00$ & $\$ 300.00$ \\
\hline $\begin{array}{l}\text { Sample 95th Percentile } \\
\text { (includes non-givers) }\end{array}$ & $\$ 4,255.00$ & $\$ 5,000.00$ & $\$ 5,000.00$ & $\$ 2,200.00$ \\
\hline Number in Sample & 4616 & 1117 & 2008 & 1491 \\
\hline $\begin{array}{l}\text { Predicted Average Gift } \\
\text { (includes non-givers) } \\
\end{array}$ & $\$ 823.00$ & $\$ 1,169.00$ & $\$ 752.00$ & $\$ 660.00$ \\
\hline
\end{tabular}




\section{Giving Across Generations: Details (continued)}

\section{Other Than Religious Gift}

\begin{tabular}{|c|c|c|c|c|}
\hline \multirow{3}{*}{$\begin{array}{l}\text { Percent who Give } \\
\text { Sample Average Gift } \\
\text { (includes non-givers) }\end{array}$} & Everyone & Prewar & Baby Boom & $\begin{array}{c}\text { Generation } \\
\text { X }\end{array}$ \\
\hline & $57.00 \%$ & $66.00 \%$ & $63.00 \%$ & $44.00 \%$ \\
\hline & $\$ 504.00$ & $\$ 620.00$ & $\$ 671.00$ & $\$ 193.00$ \\
\hline $\begin{array}{l}\text { Sample Average Gift } \\
\text { (excludes non-givers) }\end{array}$ & $\$ 878.00$ & $\$ 940.00$ & $\$ 1,064.00$ & $\$ 441.00$ \\
\hline $\begin{array}{l}\text { Sample Median Gift } \\
\text { (includes non-givers) }\end{array}$ & $\$ 60.00$ & $\$ 115.00$ & $\$ 130.00$ & $\$ 0.00$ \\
\hline $\begin{array}{l}\text { Sample Median Gift } \\
\text { (excludes non-givers) }\end{array}$ & $\$ 325.00$ & $\$ 350.00$ & $\$ 400.00$ & $\$ 200.00$ \\
\hline $\begin{array}{l}\text { Sample 95th Percentile } \\
\text { (includes non-givers) }\end{array}$ & $\$ 2,000.00$ & $\$ 2,300.00$ & $\$ 2,550.00$ & $\$ 900.00$ \\
\hline Number in Sample & 4616 & 1117 & 2008 & 1491 \\
\hline $\begin{array}{l}\text { Predicted Average Gift } \\
\text { (includes non-givers) } \\
\end{array}$ & $\$ 504.00$ & $\$ 595.00$ & $\$ 502.00$ & $\$ 439.00$ \\
\hline
\end{tabular}

Source: Steinberg and Wilhelm, 2003. 